\title{
Percutaneous Coronary Intervention After Return of Spontaneous Circulation Reduces the In-Hospital Mortality in Patients with Acute Myocardial Infarction Complicated by Cardiac Arrest
}

\author{
Jingcong Zhang $\mathbb{( D}^{1, *}$ \\ Haixia Xiong ${ }^{2} *$ \\ Jie Chen $^{3}$ \\ Qiuping Zou ${ }^{4}$ \\ Xiaoxing Liao ${ }^{5}$ \\ Yujie $\mathrm{Li}^{6}$ \\ Chunlin $\mathrm{Hu}^{6}$
}

'Department of Critical Care Medicine, The Third Affiliated Hospital of Sun Yat-sen University, Guangzhou, 510630, People's

Republic of China; ${ }^{2}$ Department of Division of Nephrology, The Third Affiliated Hospital of Sun Yat-sen University, Guangzhou, 510630, People's Republic of China;

${ }^{3}$ Department of Critical Care Medicine, the Dongguan People's Hospital, Dongguan, Province Guangdong, 523059, People's Republic of China; ${ }^{4}$ Department of Emergency Medicine the Dongguan People's Hospital, Dongguan, Province Guangdong, 523059, People's Republic of China; ${ }^{5}$ Department of Emergency Medicine, The Seventh Affiliated Hospital of Sun Yat-sen University, Shenzhen, 518107, People's Republic of China; ${ }^{6}$ Department of Emergency Medicine, The First Affiliated Hospital of Sun Yat-sen University, Guangzhou, 510080, People's Republic of China

*These authors contributed equally to this work

Correspondence: Chunlin Hu; Yujie Li Department of Emergency Medicine, The First Affiliated Hospital of Sun Yat-sen University, Guangzhou, 510080, Province Guangdong, People's Republic of China Email huchunl@mail.sysu.edu.cn; yujieligd@I63.com
Background and Objective: The role of percutaneous coronary intervention (PCI) after return of spontaneous circulation (ROSC) in patients with acute myocardial infarction (AMI) complicated by cardiac arrest $(\mathrm{CA})$ is controversial. This study aimed to evaluate the effects of PCI on the in-hospital mortality after ROSC in patients with AMI complicated by CA.

Methods: The clinical data of 66 consecutive patients with ROSC after CA caused by AMI from January 2006 to December 2015 at the First Affiliated Hospital of Sun Yat-sen University were collected. Among these patients, 21 underwent urgent PCI. We analyzed the clinical characteristics of the patients during hospitalization.

Results: The patients who underwent PCI had a higher rate of ST-segment elevation, and their initial recorded heart rhythms were more likely to have a shockable rhythm. Further, they had a high PCI success rate of $100 \%$. The in-hospital mortality in the patients who did not undergo PCI was significantly higher than that in the patients who underwent PCI $(68.9 \%$ vs $9.5 \%, P<0.05)$. Multivariate logistic regression analysis showed that cardiogenic shock (odds ratio [OR], 3.537; 95\% CI, 1.047-11.945; $P=0.042$ ) and Glasgow Coma Scale score of $\leq 8$ after ROSC (OR, 14.992; 95\% CI, 2.815-79.843; $P=0.002$ ) were the independent risk factors for in-hospital mortality among the patients. Meanwhile, PCI was a protective factor against in-hospital mortality (OR, $0.063 ; 95 \% \mathrm{CI}, 0.012-0.318 ; P=0.001$ ). After propensity matching analysis, the results still showed that PCI (OR, 0.226; 95\% CI, 0.028-1.814; $\mathrm{P}=0.0162$ ) was a protective factor for in-hospital death.

Conclusion: The patients with ROSC after CA caused by AMI who underwent PCI had a lower in-hospital mortality than those who did not undergo PCI.

Keywords: percutaneous coronary intervention, cardiac arrest, in-hospital mortality, neurological performance

\section{Introduction}

Cardiac arrest (CA) refers to the sudden termination of an individual's cardiac ejection function, which is mainly manifested as loss of consciousness and disappearance of aortic pulsation. The mortality in patients experiencing CA is very high, especially in cases occurring outside the hospital setting. ${ }^{1}$ Although many efforts have been made to prevent $\mathrm{CA}, \mathrm{CA}$ is still the leading cause of mortality in many parts of the world. ${ }^{2}$ In the absence of an evident non-cardiac cause, acute myocardial infarction (AMI) is a common cause of out-of-hospital CA (OHCA). ${ }^{3}$ Because 
percutaneous coronary intervention (PCI) can rapidly, completely, and continuously dredge the infarct-related coronary arteries, rescue the dying myocardium, and improve the prognosis of patients, it has become an important treatment method for patients with AMI. ${ }^{4,5}$ The latest consensus guidelines suggest that patients with return of spontaneous circulation (ROSC) after CA should consider receiving emergency cardiac intervention if they have STsegment elevation myocardial infarction or unstable cardiogenic shock or require mechanical circulatory support. ${ }^{6}$ However, owing to the lack of large, multi-center randomized controlled trials, the roles of PCI in patients experiencing CA caused by AMI are still controversial. ${ }^{7,8}$ To date, studies on PCI in patients with AMI complicated by CA after ROSC are still relatively rare in China. There are also differences in ethnic, regional, and medical configurations with those of other countries. Therefore, the role of PCI after ROSC in patients with AMI complicated by CA still needs to be studied. Our retrospective study aimed to investigate the effects of PCI on the in-hospital mortality of patients with ROSC after CA caused by AMI and analyze the factors related to mortality to provide a basis for clinical decision-making for these patients.

\section{Materials and Methods Research Object}

In this retrospective study, the clinical characteristics and outcomes of 66 consecutive patients resuscitated from CA caused by AMI and admitted to the First Affiliated Hospital of Sun Yat-sen University between January 2006 and December 2015 were evaluated. AMI was defined using the third edition of the universal definition of myocardial infarction published by the ESC, AHA, ACC, and WHF in 2012. ${ }^{9}$ Patients were included in the study if they fulfilled the following inclusion criteria: (1) age of $\geq 18$ years; (2) sustained ROSC, defined as ROSC lasting for 20 minutes; and (3) absence of any obvious non-cardiac cause, such as respiratory failure, metabolic disorder, stroke, hemorrhage, brain injury, electric injury, or drug overdose. For each patient fulfilling the inclusion criteria, we reviewed their medical records and documented the coronary risk factors and history of coronary artery disease. A total of 214 patients who experienced CA achieved successful resuscitation. Among them, CA was considered to be a non-cardiac cause in 116 patients (54.2\%) and a cardiac cause in 98 patients (45.8\%). Meanwhile, respiratory failure (37\%), metabolic disorder
(16\%), stroke (12\%), hemorrhage (6\%), brain injury (5\%), electric injury $(4 \%)$, drug overdose $(3 \%)$, or unknown cause $(17 \%)$ were considered to be non-cardiac causes. The cardiac causes were related to non-AMI diagnoses in 32 patients and AMI diagnoses in 66 patients. Among the patients with AMI, 10 were resuscitated from OHCA and 56 from in-hospital CA (IHCA). The study focused on these 66 patients who were resuscitated from CA caused by AMI.

\section{Treatment}

All 66 patients received cardiopulmonary resuscitation, including chest compression, external defibrillation, or endotracheal intubation by experienced physicians and nurses. Cardiogenic shock was defined as a sustained episode ( $>30 \mathrm{~min}$ ) of a systolic blood pressure of $<90 \mathrm{mmHg}$ and/or the requirement for inotropic or vasopressor drugs or mechanical support, including intra-aortic balloon pumping (IABP) or extracorporeal membrane oxygenation (ECMO), to maintain a systolic blood pressure above 90 $\mathrm{mmHg}$. Vasopressors (eg, epinephrine or dopamine) were administered when they experienced cardiogenic shock or hemodynamic instability. Antiarrhythmic drugs (eg, atropine, lidocaine, or amiodarone) were administered when the electrocardiogram (ECG) showed ventricular fibrillation (VF)/pulseless ventricular tachycardia (PVT) and pulseless electrical activity/asystole. The neurological status of the patients after ROSC was assessed using the Glasgow Coma Scale (GCS). ${ }^{10}$ For the conscious patients, aspirin $(300 \mathrm{mg})$ and clopidogrel $(300 \mathrm{mg})$ were administered preoperatively, while unfractionated heparin was administered intraoperatively. For the unconscious patients, glycoprotein IIb/IIIa receptor blockers were administered preoperatively, while unfractionated heparin was administered intraoperatively. IABP or ECMO was performed for cardiogenic shock or severe hemodynamic instability. Temporary pacemakers were used in the presence of severe bradycardia causing severe hemodynamic instability. Among the patients, 22 underwent coronary angiography (CAG), and 21 underwent subsequent PCI. PCI success was defined as a final Thrombolysis in Myocardial Infarction flow in grade three with residual stenosis of $<20 \%$. After the procedure was completed, continuous medical treatment was performed in the coronary care unit. Mild hypothermia therapy $\left(32-34^{\circ} \mathrm{C}\right)^{11}$ was provided to each patient for $24 \mathrm{~h}$ after ROSC. 


\section{Follow-Up}

During hospitalization, major adverse events were recorded in the medical records, including mortality from any cause, recurrent $\mathrm{CA}$, and gastrointestinal hemorrhage. The recovery of neurological function at the time of discharge was evaluated using the Cerebral Performance Category (CPC) scale, ${ }^{12}$ which was graded from 1 (good cerebral performance and being conscious, alert, and able to work and lead a normal life, despite possible minor psychological or neurological deficits) to 4 (permanent vegetative state, being unconscious and unaware, and no verbal or psychological interaction with the environment).

\section{Statistical Analysis}

Quantitative data with normal distribution were expressed as means $\pm \mathrm{SDs}$, and the $t$-test was used to compare the mean values between groups. Quantitative data with nonnormal distribution were expressed as medians, and the rank-sum test was used to analyze the differences between groups. Qualitative data were expressed as percentages, and the chi-square test and Fisher's exact test were used to compare the differences between groups. All demographic, clinical, angiographic, and procedural variables were initially assessed via a univariate analysis to select the predictors of in-hospital outcomes among the patients with AMI resuscitated from CA. Variables with a $P$ value of $<0.05$ were included in a multiple stepwise logistic regression model to identify the independent predictors of mortality. All analyses were performed using SPSS 21.0. Statistical significance was set at $P$ values of $<0.05$. The risk estimates for each variable were reported as odds ratios (ORs) and 95\% CIs. In order to diminish the bias between different groups, propensity score matching was performed in this study. Patients were matched based on logistic regression model. Propensity scores were estimated according to 5 important baseline characteristics including age, ST-segment elevation, Cardiogenic shock after ROSC, GCS score of $\leq 8$ after ROSC, PCI. One-toone matching was performed using a 0.2 caliper. Statistical significance was considered as a two-sided $\mathrm{P}$ value of less than 0.05 . The above statistical analysis was performed with the STATA/MP 14.0.

\section{Results}

Baseline characteristics of the study patients are described in Table 1.
The angiographic and procedural characteristics in the patients who underwent PCI are described in Table 2.

The major adverse events and clinical outcomes during hospitalization between the two cohorts are presented in Table 3.

The recovery of neurological function in the two groups of patients who survived to discharge was no significant difference between them, CPC 1 or 2, $9(64.3 \%)$ in Non-PCI group, 18 (94.7\%) in PCI group $(P>0.05)$.

There were several reasons why the non-PCI group did not receive PCI: (1) Forty patients or their families (88.9\%) rejected PCI. (2) Four patients $(8.9 \%)$ were excluded for PCI by the physician's team based on their clinical data. (3) One patient (2.2\%) was recommended for coronary artery bypass grafting.

The associated factors for in-hospital mortality after ROSC in the patients who experienced CA caused by AMI are presented in Tables 4 and 5. The significant variables in the univariate analysis $(P<0.05)$ were included in the multivariate logistic regression model. Cardiogenic shock (OR, 3.537; 95\% CI, 1.047-11.945; $P=0.042$ ) and a GCS score of $\leq 8$ after ROSC (OR, 14.992; 95\% CI, 2.815-79.843; $P=0.002$ ) were found to be the independent risk factors for in-hospital mortality in the patients with AMI complicated by CA. The patients who underwent PCI (OR, 0.063; 95\% CI, 0.012-0.318; $P=0.001$ ) had a lower risk of in-hospital mortality (protective factor) than those who did not.

After propensity matching analysis (Table 6), we found that the results still showed that PCI (OR, 0.226; 95\% CI, $0.028-1.814 ; \mathrm{P}=0.0162$ ) was a protective factor for inhospital death, while cardiogenic shock (OR, 2.499; 95\% CI, 0.284-22.009; $\mathrm{P}=0.409$ ), GCS score $\leq 8$ after resuscitation (OR, 1.984; 95\% CI, 0.168-23.369; $\mathrm{P}=0.586$ ) were still risk factors for in-hospital death, but their $\mathrm{P}$ value were not less than 0.05 , we believed that this result may be related to the small sample size of this study.

\section{Discussion}

In this complex patient population that experienced CA caused by ST-segment elevation myocardial infarction or non-STsegment elevation myocardial infarction, we found that the patients who did not receive PCI had a higher in-hospital mortality than those who did. With the deepening understanding of resuscitation in recent years, the public is becoming increasingly aware of the importance of early coronary artery reperfusion therapy for the prognosis of patients after CA caused by AMI. Thrombolytic therapy and PCI are the main 
Table I Baseline Characteristics of the Study Patients

\begin{tabular}{|c|c|c|c|c|}
\hline Variable & Overall $(n=66)$ & Non-PCI $(n=45)$ & $P C I(n=21)$ & $P$ value \\
\hline Age $(y)$ & $62.9 \pm 13.2$ & $65.8 \pm 12.3$ & $56.7 \pm 13.3$ & 0.008 \\
\hline$<65$ & $35(53.0)$ & $19(42.2)$ & $16(76.2)$ & \\
\hline$\geq 65$ & $31(47.0)$ & $26(57.8)$ & $5(23.8)$ & \\
\hline Male sex & $51(77.3)$ & $34(75.6)$ & $17(81.0)$ & 0.863 \\
\hline Smoking & $35(53.0)$ & $25(55.6)$ & $10(47.6)$ & 0.487 \\
\hline Diabetes mellitus & $22(33.0)$ & $18(40.0)$ & $4(19.0)$ & 0.082 \\
\hline Hypertension & $34(51.5)$ & $26(57.8)$ & $8(38.1)$ & 0.113 \\
\hline Chronic renal failure & $8(12.1)$ & $5(I I . I)$ & $0(0)$ & 0.267 \\
\hline Previous myocardial infarction & $10(15.1)$ & $6(13.3)$ & $4(19.0)$ & 0.843 \\
\hline Previous $\mathrm{PCl}$ & $6(9.1)$ & $5(I I . I)$ & I (4.8) & 0.688 \\
\hline Known preceding chest pain & $49(74.2)$ & $28(62.2)$ & $21(100)$ & 0.001 \\
\hline In-hospital cardiac arrest & $56(84.9)$ & $38(84.4)$ & $18(85.7)$ & 1.000 \\
\hline Arrest witnessed by a bystander & $65(98.4)$ & $44(97.8)$ & $21(100)$ & 1.000 \\
\hline Bystander CPR & $58(87.9)$ & $39(86.7)$ & $19(90.5)$ & 0.971 \\
\hline Time from cardiac arrest to BLS (min) (mean $\pm S D)$ & $2.17 \pm 3.12$ & $2.23 \pm 3.20$ & $2.05 \pm 3.01$ & 0.830 \\
\hline Time from cardiac arrest to ROSC (min) (mean \pm SD) & $32.67 \pm 25.53$ & $35.86 \pm 25.53$ & $26.11 \pm 24.94$ & 0.186 \\
\hline Initial recorded rhythm (VF/PVT) & $4 I(62 . I)$ & $22(48.9)$ & $19(90.5)$ & 0.001 \\
\hline Use of vasopressors & $47(71.2)$ & 40 (88.9) & $7(33.3)$ & $<0.001$ \\
\hline Use of antiarrhythmic drugs & $57(86.3)$ & $43(95.6)$ & $14(66.7)$ & 0.004 \\
\hline ST-segment elevation & $35(53.0)$ & $18(40.0)$ & $17(81.0)$ & $<0.001$ \\
\hline Cardiogenic shock after ROSC & 29 (43.9) & $25(55.6)$ & $4(19.0)$ & 0.005 \\
\hline GCS score of $\leq 8$ after ROSC & $31(47.0)$ & $29(64.4)$ & $2(9.5)$ & 0.002 \\
\hline
\end{tabular}

Note: Values are expressed as mean numbers with percentages of the total in parentheses, except those indicated otherwise.

Abbreviations: PCI, percutaneous coronary intervention; CPR, cardiopulmonary resuscitation; BLS, basic life support; ROSC, return of spontaneous circulation; VF, ventricular fibrillation; PVT, pulseless ventricular tachycardia; GCS, Glasgow Coma Scale.

treatments for early coronary reperfusion. The vast majority of patients who experience sudden CA need extrathoracic compressions; however, long-term extrathoracic compressions are one of the contraindications of thrombolytic therapy. ${ }^{13}$ Further, there are many contraindications for thrombolytic therapy, such as recent active visceral hemorrhage, stroke, major surgery, pregnancy, active peptic ulcer, or allergy to thrombolytic drugs. In this study, three patients who did not receive PCI but received thrombolytic therapy did not have a good prognosis. This is consistent with the conclusions of Spohr et al and Stadlbauer et al. ${ }^{14,15}$

This study showed that the average age of the patients in the non-PCI group was higher than that in the PCI group $(P<0.05)$. This difference suggests that age may be an important factor influencing emergency physicians and interventional cardiologists in deciding whether to perform PCI in daily clinical work. Since most studies have shown that among patients who experience sudden $\mathrm{CA}$, older patients who receive PCI have a poorer prognosis than younger patients. ${ }^{16-18}$ The ECG findings after resuscitation were also significantly different between the two groups: $81 \%$ of the patients in the PCI group and only $40 \%$ of the patients in the non-PCI group had ST-segment elevation, which is similar to the study findings of Zanuttini et al. ${ }^{19}$ This difference suggests that in the daily work in the hospital, emergency physicians and interventional cardiologists may decide whether to perform CAG and PCI based on the ECG results after resuscitation. However, Redfors et al found that approximately $40 \%$ of patients without ST-segment elevation after CA and resuscitation had acute coronary artery occlusion. ${ }^{20}$ Moreover, this study showed that in the patients without ST-segment elevation after resuscitation, there was no significant difference in the in-hospital mortality between those who received PCI and those who did not $(P=0.272)$, which is similar to the data reported by Wester et $\mathrm{al}^{21}$ however, some studies have shown that emergency PCI can improve the survival rate and neurological prognosis of patients who experience OHCA without ST-segment elevation. $^{22,23}$ A randomized, multi-center trial showed that emergency $\mathrm{CAG}$ did not improve survival in patients with ROSC after OHCA without ST-segment elevation. ${ }^{24}$ 
Table 2 Angiographic and Procedural Characteristics in the Patients Who Underwent $\mathrm{PCl}$

\begin{tabular}{|l|l|}
\hline Variable & n (\%) \\
\hline $\begin{array}{l}\text { Time from cardiac arrest to balloon inflation } \\
<6 \mathrm{~h}\end{array}$ & $10(47.7)$ \\
$6-24 \mathrm{~h}$ & $0(0)$ \\
$>24 \mathrm{~h}$ & $1 \mathrm{I}(52.3)$ \\
\hline $\begin{array}{l}\text { Significant coronary lesions } \\
\text { Single-vessel }\end{array}$ & \\
Double-vessel & $10(47.6)$ \\
Three-vessel & $6(28.6)$ \\
\hline Infarct-related vessel & $5(23.8)$ \\
\hline Left main & \\
Left anterior descending & $0(0)$ \\
Left circumflex & $6(28.6)$ \\
Right coronary artery & $1(4.7)$ \\
\hline Stenting & $14(66.7)$ \\
PTCA & $19(90.5)$ \\
Thrombus aspiration & $2(9.5)$ \\
Pre-PCl TIMl grade 0 to 2 & $8(38.1)$ \\
PCl success & $21(100)$ \\
GP IIb/Illa inhibitors & $21(100)$ \\
\hline
\end{tabular}

Note: Values are expressed as mean numbers with percentages of the total in parentheses, except where indicated otherwise.

Abbreviations: $\mathrm{PCl}$, percutaneous coronary intervention; PTCA, percutaneous transluminal coronary angioplasty; TIMI, thrombolysis in myocardial infarction; GP, glycoprotein.

Therefore, the role of emergency CAG and PCI in patients who experience CA without ST-segment elevation remains to be confirmed.

Our study found that cardiogenic shock (OR, 3.537; 95\% CI, 1.047-11.945; $P=0.042)$ and a GCS score of $\leq 8$ after ROSC (OR, 14.992; 95\% CI, 2.815-79.843; $P=0.002)$ were the independent risk factors for inhospital mortality in the patients with ROSC after CA caused by AMI, which is consistent with the results of

Table 3 Comparison of the Major Adverse Events and Clinical Outcomes During Hospitalization Between the Two Groups

\begin{tabular}{|l|l|l|l|}
\hline Variable & $\begin{array}{l}\text { Non-PCI } \\
(\mathbf{n = 4 5 )}\end{array}$ & $\begin{array}{l}\text { PCI } \\
(\mathbf{n}=\mathbf{2} \text { I) }\end{array}$ & P value \\
\hline Gastrointestinal hemorrhage & $8(17.8)$ & $\mathrm{I}(4.8)$ & 0.294 \\
Recurrent cardiac arrest & $2 \mathrm{I}(46.7)$ & $3(14.3)$ & $0.01 \mathrm{I}$ \\
In-hospital mortality & $3 \mathrm{I}(68.9)$ & $2(9.5)$ & $<0.00 \mathrm{I}$ \\
$\quad$ Men & $24(70.6)$ & $\mathrm{I}(5.9)$ & \\
Women & $7(63.6)$ & $\mathrm{I}(25.0)$ & \\
\hline
\end{tabular}

Note: Data are presented as numbers with percentages in parentheses, unless otherwise stated. previous studies. ${ }^{25,26}$ Lettieri et al showed that cardiogenic shock on admission is an independent risk factor for inhospital mortality in patients who experienced OHCA caused by acute ST-segment elevation myocardial infarction (OR, 3.05; 95\% CI, 1.04-8.91; $P=0.035){ }^{27}$

Similarly, Omer et al showed that among 499 patients who experienced CA caused by ST-segment elevation myocardial infarction, the in-hospital mortality of patients with cardiogenic shock was as high as $44 \%$, while that of patients without cardiogenic shock was only $19 \%{ }^{28}$ In the present study, even the use of IABP failed to reduce inhospital mortality in patients with cardiogenic shock due to acute myocardial infarction, although this conclusion was not clear due to the small sample size, but similar findings have been reported in studies. ${ }^{29}$ In the studies by Lettieri et al and Pan et al, the state of neurological function after ROSC is also an independent risk factor for inhospital mortality. ${ }^{27,30}$ However, it is important to note that the neurological impairment in these patients can be attributed almost entirely to the prolonged cerebral hypoxia caused by CA. However, we could not determine whether their neurological impairment was attributed to hypoxia alone or the ischemic complications during hospitalization. This study found that PCI (OR, 0.063; 95\% CI, 0.012-0.318; $P=0.001)$ can reduce the in-hospital mortality after ROSC of patients who experienced CA caused by AMI, which is consistent with the results of multiple observational studies..$^{16,23,31}$ Some case reports have described that PCI can improve survival and neurological prognosis despite long-term cardiopulmonary resuscitation. $^{32,33}$ The success rate of PCI in this study was as high as $100 \%$, which further confirms that PCI is effective and feasible in such patients. In this study, all patients who underwent PCI within $6 \mathrm{~h}$ of CA survived to discharge, suggesting that early PCI may be more beneficial to survival. This is consistent with previous study findings, ${ }^{34-36}$ although the definition of "early" is still controversial. A study suggests that only patients who experience CA with unstable lesions (chest pain, absence of coronary artery disease history, ST-segment elevation, and initial shockable rhythm) can benefit from early PCI. ${ }^{37}$

To better treat such patients, we also analyzed other risk factors related to in-hospital mortality. This study showed no significant difference in the time from CA to basic life support and the time from CA to ROSC between the patients who died during hospitalization and those who survived to discharge, which is different from the results of Lim et $\mathrm{al}^{25}$ this may be related to the fact that 
Table 4 Associated Factors of In-Hospital Mortality in the Patients with Acute Myocardial Infarction Complicated by Cardiac Arrest After ROSC

\begin{tabular}{|c|c|c|c|}
\hline Variable & Mortality $(n=33)$ & Survival $(n=33)$ & $P$ value \\
\hline Age (y) & $67.21 \pm 11.89$ & $58.52 \pm 13.25$ & 0.007 \\
\hline$<65$ & $13(39.4)$ & $22(66.7)$ & \\
\hline$\geq 65$ & $20(60.6)$ & II (33.3) & \\
\hline Male sex & $25(75.8)$ & $26(78.8)$ & 0.769 \\
\hline Smoking & $17(5 \mid .5)$ & $18(54.5)$ & 0.909 \\
\hline Diabetes mellitus & $14(42.4)$ & $8(24.2)$ & 0.097 \\
\hline Hypertension & $18(54.5)$ & $16(48.5)$ & 0.531 \\
\hline Chronic renal failure & $6(18.2)$ & $2(6.1)$ & 0.238 \\
\hline Previous myocardial infarction & $5(15.2)$ & $5(15.2)$ & 1.000 \\
\hline Previous $\mathrm{PCl}$ & $4(12.1)$ & $2(6.1)$ & 0.640 \\
\hline Known preceding chest pain & $25(75.8)$ & $24(72.7)$ & 0.778 \\
\hline In-hospital cardiac arrest & $29(87.9)$ & $27(81.8)$ & 0.731 \\
\hline Arrest witnessed by a bystander & $33(100)$ & $32(97.0)$ & 1.000 \\
\hline Bystander CPR & $30(90.9)$ & $28(84.8)$ & 0.706 \\
\hline Time from cardiac arrest to BLS $(\mathrm{min})($ mean $\pm \mathrm{SD})$ & $2.18 \pm 3.24$ & $2.16 \pm 3.04$ & 0.974 \\
\hline Time from cardiac arrest to ROSC (min) (mean \pm SD) & $37.34 \pm 26.31$ & $27.46 \pm 24.05$ & 0.153 \\
\hline Initial recorded rhythm (VF/PVT) & $15(45.5)$ & $26(78.8)$ & 0.005 \\
\hline Use of vasopressors & $30(90.9)$ & $17(5 \mid .5)$ & $<0.001$ \\
\hline Use of antiarrhythmic drugs & $32(97.0)$ & $25(75.8)$ & 0.031 \\
\hline ST-segment elevation & $14(42.4)$ & $21(63.6)$ & 0.084 \\
\hline Cardiogenic shock after ROSC & $21(63.6)$ & $8(24.2)$ & 0.001 \\
\hline GCS score of $\leq 8$ after ROSC & $25(75.8)$ & $6(18.2)$ & $<0.001$ \\
\hline Temporary pacemakers & $6(18.2)$ & $6(18.2)$ & 1.000 \\
\hline IABP & $7(2 \mid .2)$ & $3(9.1)$ & 0.303 \\
\hline Mechanical ventilation & $30(90.9)$ & I8 (54.5) & 0.001 \\
\hline $\mathrm{PCl}$ & $2(6.1)$ & $19(57.6)$ & $<0.001$ \\
\hline Thrombolysis & $3(9.1)$ & $2(6.1)$ & 1.000 \\
\hline Mild hypothermia therapy & $7(2 \mid .2)$ & $3(9.1)$ & 0.303 \\
\hline
\end{tabular}

Note: Data are presented as numbers with percentages in parentheses, unless otherwise stated.

Abbreviations: ROSC, return of spontaneous circulation; PCl, percutaneous coronary intervention; CPR, cardiopulmonary resuscitation; BLS, basic life support; VF, ventricular fibrillation; PVT, pulseless ventricular tachycardia; GCS, Glasgow Coma Scale; IABP, intra-aortic balloon pumping.

most of the patients $(84.8 \%)$ in this study had an IHCA. Patients who experience IHCA are more likely to be witnessed by medical staff when they collapse, are surrounded by more medical equipment, and can receive professional treatment earlier than patients who experience OHCA. This study showed that the patients who survived to discharge had a higher rate of shockable rhythm (VF/PVT) than those who died during hospitalization ( $78.8 \%$ vs $45.5 \%, P<0.05)$, which is consistent with the results of Lettieri et al. ${ }^{27}$ Previous studies have shown that the presence of shockable rhythms (VF/PVT) can improve the success rate of ROSC in patients who

Table 5 Multivariate Logistic Regression Analysis for the Independent Risk Factors of In-Hospital Mortality After ROSC in the Patients with Acute Myocardial Infarction Complicated by Cardiac Arrest

\begin{tabular}{|l|l|l|l|l|l|}
\hline \multirow{2}{*}{ Variable } & & & & \multicolumn{2}{|c|}{$95 \%$ CI } \\
\cline { 2 - 6 } & B & Sig. & Exp (B) & Lower Limits & Upper Limits \\
\hline Cardiogenic shock after ROSC & 1.263 & 0.042 & 3.537 & 1.047 & 11.945 \\
GCS score of $\leq 8$ after ROSC & 2.707 & 0.002 & 14.992 & 2.815 & 79.843 \\
PCl & -2.771 & 0.001 & 0.063 & 0.012 & 0.318 \\
\hline
\end{tabular}

Abbreviations: ROSC, return of spontaneous circulation; GCS, Glasgow Coma Scale; PCl, percutaneous coronary intervention. 
Table 6 Multivariate Logistic Regression Analysis for the Independent Risk Factors of In-Hospital Mortality After ROSC in the Patients with Acute Myocardial Infarction Complicated by Cardiac Arrest (After Propensity Score Matching)

\begin{tabular}{|l|l|l|l|l|l|}
\hline \multirow{2}{*}{ Variable } & & & & \multicolumn{2}{|c|}{$95 \%$ CI } \\
\cline { 2 - 6 } & B & Sig. & Exp (B) & Lower Limits & Upper Limits \\
\hline Cardiogenic shock after ROSC & 0.916 & 0.409 & 2.499 & 0.284 & 22.009 \\
GCS score of $\leq 8$ after ROSC & 0.685 & 0.586 & 1.984 & 0.168 & 23.369 \\
PCI & -1.486 & 0.0162 & 0.226 & 0.028 & 1.814 \\
\hline
\end{tabular}

Abbreviations: ROSC, return of spontaneous circulation; GCS, Glasgow Coma Scale; PCl, percutaneous coronary intervention.

experience $\mathrm{CA}$ and the prognosis of those who receive PCI. ${ }^{38,39}$ The presence of non-shockable rhythms is usually attributed to the failure of patients to receive timely and effective cardiopulmonary resuscitation, resulting in long-term myocardial ischemia and hypoxia; therefore, the probability of survival to discharge is lower. ${ }^{40}$ It is then necessary to popularize medical first aid knowledge to the public and configure first-aid equipment in public places, so that patients can receive effective cardiopulmonary resuscitation as soon as possible. Conversely, the presence of non-shockable rhythms may also be attributed to multi-vessel lesions of the coronary artery or left main coronary artery infarction, and the heart injury in these patients is more extensive and severe. This study showed that mild hypothermia therapy does not improve the survival and neurological outcome of patients with a GCS score of $\leq 8$ after ROSC, which is inconsistent with the results of a previous systematic review of multiple randomized trials. ${ }^{41}$ This result may be related to the small number of patients included in our study and the small number of patients who received mild hypothermia.

In this study, we compared the neurological function between the PCI and non-PCI groups. The analysis showed that although the rate of good functional neurological recovery (CPC 1 or 2 ) in the PCI group was higher than that in the non-PCI group, there was no significant difference found between them $(94.7 \%$ vs $64.3 \%$, $P=0.074$ ), which is inconsistent with previous results. ${ }^{22}$ This result may be related to the small number of patients included in our study.

After analyzing the angiographic data of the patients undergoing PCI, we found that the infarct-related artery in most of them was the right coronary artery (66.7\%). In the studies by Lettieri et al and Kunadian et al, the infarctrelated artery in most patients was the left anterior descending artery (53\% and $46.5 \%$, respectively); meanwhile, the infarct-related artery in a few patients was the left main artery ( $1 \%$ and $2.5 \%$, respectively). ${ }^{27,42}$ This result may be related to the strong adaptability of the right coronary artery to ischemia and hypoxia, and patients have more time to receive early treatment after the onset of symptoms. In contrast, AMI with the involvement of the left main artery develops rapidly and is often complicated by cardiogenic shock, and patients are more likely to die in a short period. ${ }^{43}$ Patients whose infarct-related artery is the left main artery may find it difficult to achieve ROSC after $\mathrm{CA}$; thus, they miss the opportunity to undergo CAG and PCI.

\section{Limitation}

First, this study was a single-center, retrospective, observational study; thus, causality cannot be confirmed. Second, owing to the incompleteness of some medical records, there may be some lack of information and bias. Finally, the number of cases included in this study was small, and there was a lack of long-term follow-up data.

\section{Conclusion}

In this complex patient population that experienced CA caused by ST-segment elevation myocardial infarction or non-ST-segment elevation myocardial infarction, we found that the patients who did not receive PCI had a higher inhospital mortality than those who did.

\section{Ethical Approval}

The patients or the patients' next of kin provided their written informed consent to participate in this study. The data was anonymized or maintained with confidentiality. The publication of this study is in accordance with the Declaration of Helsinki. Ethical review and approval was not required for the retrospective study on human participants in accordance with the local legislation and institutional requirements. The study is exempt from the 
approval of the ethics committee of the Third Affiliated Hospital of Sun Yat-sen University.

\section{Acknowledgments}

This study was supported by funding from the Shenzhen Science and Technology R\&D Project (Grant No. JCYJ20160608142215491) and the Guangdong Province Basic and Applied Basic Research Fund Project (Grant No. 2020A1515010120). The funders had no role in the study design, data collection, analysis, decision to publish, or preparation of the manuscript.

\section{Disclosure}

The authors declare that they have no conflicts of interest.

\section{References}

1. Chan PS, McNally B, Tang F, Kellermann A. Recent trends in survival from out-of-hospital cardiac arrest in the United States. Circulation. 2014;130(21):1876-1882. doi:10.1161/CIRCULATIONAHA.114.00 9711

2. Markenson D, Ferguson JD, Chameides L, et al. Part 13: first aid: 2010 American Heart Association and American red cross international consensus on first aid science with treatment recommendations. Circulation. 2010;122(16 Suppl 2):S582-S605. doi:10.1161/ CIRCULATIONAHA. 110.971168

3. Spaulding CM, Joly LM, Rosenberg A, et al. Immediate coronary angiography in survivors of out-of-hospital cardiac arrest. $N$ Engl $J$ Med. 1997;336(23):1629-1633. doi:10.1056/NEJM199706053 362302

4. Van de Werf F, Bax J, Betriu A, et al. Management of acute myocardial infarction in patients presenting with persistent ST-segment elevation: the task force on the management of ST-segment elevation acute Myocardial Infarction of the European Society of Cardiology. Eur Heart J. 2008;29(23):2909-2945.

5. Grines CL, Browne KF, Marco J, et al. A comparison of immediate angioplasty with thrombolytic therapy for acute myocardial infarction. The primary angioplasty in Myocardial Infarction Study Group. $N$ Engl J Med. 1993;328(10):673-679. doi:10.1056/NEJM199303113281001

6. Panchal AR, Bartos JA, Cabanas JG, et al. Part 3: adult basic and advanced life support: 2020 American Heart Association guidelines for cardiopulmonary resuscitation and emergency cardiovascular care. Circulation. 2020;142(16_suppl_2):S366-S468.

7. Anyfantakis ZA, Baron G, Aubry P, et al. Acute coronary angiographic findings in survivors of out-of-hospital cardiac arrest. $\mathrm{Am}$ Heart J. 2009;157(2):312-318. doi:10.1016/j.ahj.2008.09.016

8. Kahn JK, Glazier S, Swor R, Savas V, O’Neill WW. Primary coronary angioplasty for acute myocardial infarction complicated by out-of-hospital cardiac arrest. Am $J$ Cardiol. 1995;75 (15):1069-1070. doi:10.1016/S0002-9149(99)80727-9

9. Thygesen K, Alpert JS, Jaffe AS, et al. Third universal definition of myocardial infarction. Circulation. 2012;126(16):2020-2035. doi:10.1161/CIR.0b013e31826e1058

10. Teasdale G, Murray G, Parker L, Jennett B. Adding up the Glasgow Coma Score. Acta Neurochir Suppl. 1979;28(1):13-16.

11. Nolan JP, Morley PT, Vanden HT, et al. Therapeutic hypothermia after cardiac arrest: an advisory statement by the advanced life support task force of the International Liaison committee on resuscitation. Circulation. 2003;108(1):118-121. doi:10.1161/01. CIR.0000079019.02601.90
12. Morrison LJ, Visentin LM, Kiss A, et al. Validation of a rule for termination of resuscitation in out-of-hospital cardiac arrest. $N$ Engl $J$ Med. 2006;355(5):478-487. doi:10.1056/NEJMoa052620

13. Curzen N, Haque R, Timmis A. Applications of thrombolytic therapy. Intensive Care Med. 1998;24(8):756-768. doi:10.1007/ s001340050663

14. Spohr F, Arntz HR, Bluhmki E, et al. International multicentre trial protocol to assess the efficacy and safety of tenecteplase during cardiopulmonary resuscitation in patients with out-of-hospital cardiac arrest: the Thrombolysis in Cardiac Arrest (TROICA) Study. Eur J Clin Invest. 2005;35(5):315-323. doi:10.1111/j.1365-2362.2005.01491.x

15. Stadlbauer KH, Krismer AC, Arntz HR, et al. Effects of thrombolysis during out-of-hospital cardiopulmonary resuscitation. Am J Cardiol. 2006;97(3):305-308. doi:10.1016/j.amjcard.2005.08.045

16. Dumas F, Cariou A, Manzo-Silberman S, et al. Immediate percutaneous coronary intervention is associated with better survival after out-ofhospital cardiac arrest: insights from the PROCAT (Parisian Region Out of hospital Cardiac ArresT) registry. Circ Cardiovasc Interv. 2010;3(3):200-207. doi:10.1161/CIRCINTERVENTIONS.109.913665

17. Cronier P, Vignon P, Bouferrache K, et al. Impact of routine percutaneous coronary intervention after out-of-hospital cardiac arrest due to ventricular fibrillation. Crit Care. 2011;15(3):R122. doi:10.1186/ cc 10227

18. Mager A, Kornowski R, Murninkas D, et al. Outcome of emergency percutaneous coronary intervention for acute ST-elevation myocardial infarction complicated by cardiac arrest. Coron Artery Dis. 2008;19(8):615-618. doi:10.1097/MCA.0b013e32831381b4

19. Zanuttini D, Armellini I, Nucifora G, et al. Impact of emergency coronary angiography on in-hospital outcome of unconscious survivors after out-of-hospital cardiac arrest. Am J Cardiol. 2012;110 (12):1723-1728. doi:10.1016/j.amjcard.2012.08.006

20. Redfors B, Ramunddal T, Angeras O, et al. Angiographic findings and survival in patients undergoing coronary angiography due to sudden cardiac arrest in western Sweden. Resuscitation. 2015;90:13-20. doi:10.1016/j.resuscitation.2014.11.034

21. Wester A, Mohammad MA, Andell P, et al. Coronary angiographic findings and outcomes in patients with sudden cardiac arrest without ST-elevation myocardial infarction: a SWEDEHEART study. Resuscitation. 2018;126:172-178. doi:10.1016/j.resuscitation.2018.01.044

22. Patel N, Patel NJ, Macon CJ, et al. Trends and outcomes of coronary angiography and percutaneous coronary intervention after out-ofhospital cardiac arrest associated with ventricular fibrillation or pulseless ventricular tachycardia. JAMA Cardiol. 2016;1(8):890-899. doi:10.1001/jamacardio.2016.2860

23. Dumas F, Bougouin W, Geri G, et al. Emergency percutaneous coronary intervention in post-cardiac arrest patients without ST-segment elevation pattern: insights from the PROCAT II registry. JACC Cardiovasc Interv. 2016;9(10):1011-1018. doi:10.1016/j.jcin.2016.02.001

24. Lemkes JS, Janssens GN, van Royen N. Coronary angiography after cardiac arrest without ST-segment elevation. $N$ Engl J Med. 2019;381 (2):189-190.

25. Lim HS, Stub D, Ajani AE, et al. Survival in patients with myocardial infarction complicated by out-of-hospital cardiac arrest undergoing emergency percutaneous coronary intervention. Int $J$ Cardiol. 2013;166(2):425-430.

26. Garot P, Lefevre T, Eltchaninoff $\mathrm{H}$, et al. Six-month outcome of emergency percutaneous coronary intervention in resuscitated patients after cardiac arrest complicating ST-elevation myocardial infarction. Circulation. 2007;115(11):1354-1362. doi:10.1161/ CIRCULATIONAHA.106.657619

27. Lettieri C, Savonitto S, De Servi S, et al. Emergency percutaneous coronary intervention in patients with ST-elevation myocardial infarction complicated by out-of-hospital cardiac arrest: early and medium-term outcome. Am Heart J. 2009;157(3):569-575. doi:10.1016/j.ahj.2008.10.018 
28. Omer MA, Tyler JM, Henry TD, et al. Clinical characteristics and outcomes of STEMI patients with cardiogenic shock and cardiac arrest. JACC Cardiovasc Interv. 2020;13(10):1211-1219. doi:10.1016/j.jcin.2020.04.004

29. Hayiroglu MI, Canga Y, Yildirimturk O, et al. Clinical characteristics and outcomes of acute coronary syndrome patients with intra-aortic balloon pump inserted in intensive cardiac care unit of a tertiary clinic. Turk Kardiyol Dern Ars. 2018;46(1):10-17.

30. Pan W, Yang SS, Wang LF, et al. [Outcome of patients with ST-elevation myocardial infarction complicated by pre-hospital cardiac arrest underwent emergency percutaneous coronary intervention]. Zhonghua Xin Xue Guan Bing Za Zhi. 2010;38 (10):875-879. Chinese.

31. Geri G, Dumas F, Bougouin W, et al. Immediate percutaneous coronary intervention is associated with improved short- and long-term survival after out-of-hospital cardiac arrest. Circ Cardiovasc Interv. 2015;8(10):e002303. CIRCINTERVENTIONS.114.002303

32. Zimmermann S, Rohde D, Marwan M, Ludwig J, Achenbach S. Complete recovery after out-of-hospital cardiac arrest with prolonged (59 min) mechanical cardiopulmonary resuscitation, mild therapeutic hypothermia and complex percutaneous coronary intervention for ST-elevation myocardial infarction. Heart Lung. 2014;43(1):62-65. doi:10.1016/j.hrtlng.2013.10.011

33. Burnett AM, Frascone RJ, Brechtken J, Warren D, Roach B, Zinkel AR. A case of neurologically intact survival after 2 hours and 50 minutes of euthermic cardiac arrest treated with mechanical CPR and intra-arrest percutaneous coronary intervention. Prehosp Emerg Care. 2019;23(3):430-433. doi:10.1080/10903127.20 18.1506842

34. Vyas A, Chan PS, Cram P, Nallamothu BK, McNally B, Girotra S. Early coronary angiography and survival after out-of-hospital cardiac arrest. Circ Cardiovasc Interv. 2015;8(10). doi:10.1161/CIRCINTER VENTIONS.114.002321

35. Kern KB, Lotun K, Patel N, et al. Outcomes of comatose cardiac arrest survivors with and without ST-segment elevation myocardial infarction: importance of coronary angiography. JACC Cardiovasc Interv. 2015;8(8):1031-1040. doi:10.1016/j.jcin.2015.02.021
36. Jentzer JC, Scutella M, Pike F, et al. Early coronary angiography and percutaneous coronary intervention are associated with improved outcomes after out of hospital cardiac arrest. Resuscitation. 2018;123:15-21. doi:10.1016/j.resuscitation.2017.12.004

37. Pechmajou L, Marijon E, Varenne O, et al. Impact of coronary lesion stability on the benefit of emergent percutaneous coronary intervention after sudden cardiac arrest. Circ Cardiovasc Interv. 2020;13(9): e9181. doi:10.1161/CIRCINTERVENTIONS.119.009181

38. Mooney MR, Unger BT, Boland LL, et al. Therapeutic hypothermia after out-of-hospital cardiac arrest: evaluation of a regional system to increase access to cooling. Circulation. 2011;124(2):206-214. doi:10.1161/CIRCULATIONAHA.110.986257

39. Taglieri N, Saia F, Bacchi RM, et al. Prognostic significance of shockable and non-shockable cardiac arrest in ST-segment elevation myocardial infarction patients undergoing primary angioplasty. Resuscitation. 2018;123:8-14. doi:10.1016/j.resuscitation.20 17.12 .006

40. Li YQ, Sun SJ, Liu N, et al. Comparing percutaneous coronary intervention and thrombolysis in patients with return of spontaneous circulation after cardiac arrest. Clinics. 2013;68(4):523-529. doi:10.6061/clinics/2013(04)14

41. Donnino MW, Andersen LW, Berg KM, et al. Temperature management after cardiac arrest: an advisory statement by the advanced life support task force of the International Liaison committee on resuscitation and the American Heart Association emergency cardiovascular care committee and the council on cardiopulmonary, critical care, perioperative and resuscitation. Circulation. 2015;132 (25):2448-2456

42. Kunadian V, Bawamia B, Maznyczka A, Zaman A, Qiu W. Outcomes following primary percutaneous coronary intervention in the setting of cardiac arrest: a registry database study. Eur Heart J Acute Cardiovasc Care. 2015;4(1):6-15. doi:10.1177/2048872614534079

43. Lee SW, Hong MK, Lee CW, et al. Early and late clinical outcomes after primary stenting of the unprotected left main coronary artery stenosis in the setting of acute myocardial infarction. Int J Cardiol. 2004;97(1):73-76. doi:10.1016/j.ijcard.2003.07.034
International Journal of General Medicine

\section{Publish your work in this journal}

The International Journal of General Medicine is an international, peer-reviewed open-access journal that focuses on general and internal medicine, pathogenesis, epidemiology, diagnosis, monitoring and treatment protocols. The journal is characterized by the rapid reporting of reviews, original research and clinical studies across all disease areas. The manuscript management system is completely online and includes a very quick and fair peer-review system, which is all easy to use. Visit http://www.dovepress.com/ testimonials.php to read real quotes from published authors. 